\title{
PERFORMANCE-BASED-MAINTENANCE: A COMPARATIVE STUDY BETWEEN THE NETHERLANDS AND ISRAEL
}

\author{
Igal M. SHOHET ${ }^{1}$ and Ad STRAUB ${ }^{2}$ \\ ${ }^{1}$ Department of Structural Engineering, Faculty of Engineering Sciences, Ben-Gurion \\ University of the Negev, P.O. Box 653, Beer Sheva 84105, Israel \\ E-Mail: igals@bgu.ac.il \\ ${ }^{2}$ OTB Research Institute for Housing, Urban and Mobility Studies, Delft University of \\ Technology, P.O. Box 5030, Delft 2600 GA, The Netherlands \\ E-mail: A.Straub@tudelft.nl
}

Received 1 April 2012; accepted 26 June 2012

\begin{abstract}
Traditional maintenance contracts using the unit price system and prescriptive specifications are simple in their structure and implementation. Implementation of prescriptive-based specification reduces though the flexibility of the procurement and limits the possibilities of the contractor to improve the in-sight operation. Furthermore, the management of the contract faces difficulties such as poor performance of the buildings and ineffective contract management. Performance-Based-Maintenance (PBM) attains an alternative means for outsourcing of maintenance. The objective of the study was to comparatively assess the state-of-the-art of PBM between the Netherlands and Israel, with the focus on performance of public facilities and cost of the service. Pilot studies, carried out in the Netherlands and Israel, reveal that PBM attains high potential of cost-savings (20\%) and improved performance. The paper concludes with provision of a future bidding system for PBM contracts.
\end{abstract}

KEYWORDS: Contracts; Maintenance; Outsourcing; Performance; Public sector

REFERENCE to this paper should be made as follows: Shohet, I. M. and Straub, Ad (2013) Performance-based-maintenance: A comparative study between the Netherlands and Israel, International Journal of Strategic Property Management, 17(2), pp. 199-209.

\section{INTRODUCTION}

Traditional maintenance contracts using the unit price system and prescriptive specifications are simple in their structure and implementation. Nevertheless the management of the contract faces difficulties such as poor performance of the buildings (Stenbeck, 2008). PBM offers an outline for systematic transfer of facilities between different contracts as well as a platform for management of the contract, and the elimination of change-orders. The performance concept in construction implies that the demands of the buildings are specified according to the outcomes of the process rather than according to prescribed detail of activities. This concept of specification allows concentrating in the outcomes and leaves flexibility for the contractor and the designer of the service/activity.

PBM Contracts are based on the following principles: (a) performance model; (b) preventive maintenance and rehabilitation model; (c) Pricing model; and (d) Risk sharing model (Cheng and Leu, 2008; Damnjanovic and Zhang, 2008; Lugtigheid et al., 2007). Four parameters are identified as the core drivers for PBM (Shohet, 2006): (a) Expectations to develop effective procurement methods; (b) Performance Based Maintenance as a driver

Copyright (C) 2013 Vilnius Gediminas Technical University (VGTU) Press Technika http://www.tandfonline.com/TSPM 
to meet the end-user needs; (c) Establishment of an effective tendering system composed of core criteria for pre-qualification of contractors and of bid-winning criteria that will ensure the quality of the services provided, and (d) Establishment of a decisive mechanism for transferring the facility from former to successor contractor.

\section{DUTCH HOUSING ASSOCIATIONS}

Dutch housing associations have a market share of about $33 \%$ of the entire Dutch housing stock. Relatively speaking, it is the largest social rented sector in the European Union and maybe in the world. Over 400 Dutch social landlords own more than 2.4 million dwelling units, and have a total annual turnover of around 13.5 billion Euros. Together, Dutch housing associations spend over 4 billion Euros annually on maintenance and improvement of dwellings. External suppliers of maintenance and improvement services account for approximately $90 \%$ of the annual turnover.

In the Netherlands, the Housing Act of 1901 provides the public framework for housing associations' activities. These social enterprises fulfil a public function combined with what are more or less commercial activities. During the 1990s Dutch housing associations were transformed into so-called hybrid organisations, "combining task organization (implementing public tasks) and market organization (meeting market demands)" (Priemus, 2001: 247). Both their market and task operations forced housing associations to adopt a more structured approach to measuring and monitoring their performance. The drive towards more professional standards led to the adaptation of private sector approaches to public housing management (Nieboer and Gruis, 2004).

The professionalism of Dutch housing associations has led to paying more attention to maintenance and partnerships in the supply chain of maintenance, leading to PBM contracts too. Technical construction legislation sets only the lower limits for the housing quality level. In any case, all dwellings have to satisfy the minimal requirement of the Dutch Building Decree. The housing associations are permitted to use long term PBM contracts, because European legislation for public tendering is not mandatory for them.

For public facilities new legislation for environmental public procurement has been put in operation in 2010. This legislation gives preference to performance-based procurement of the maintenance of facilities.

\subsection{Performance-Based-Maintenance (PBM)}

Generally, the objectives of housing associations in the implementation of PBM contracting are (Straub, 2007):

- achieving budget certainty and cost savings;

- improving product quality;

- simplifying the maintenance management process; and

- promoting innovation by maintenance contractors.

Maintenance contractors emphasise performance, time, and cost improvements by having continuity in ordering, and a better understanding of the needs of housing associations by PBM. Long term partnering for periods of 4-8 years provide the possibility of balancing exterior summer activities with interior winter activities, providing contractors with levelled maintenance resources throughout the year. This allows the contractor to employ its workers full-time, enabling them to plan and invest in training and continuous development. Moreover, long term contracts reduce significantly the overhead costs of managing the contract.

Continuity enables maintenance services to be offered at the best level of quality, understanding the performance needs of housing associations, monitoring degradation, and making use of Life Cycle Costing (LCC) and total costs of ownership principles.

PBM contracts applied by Dutch housing associations are based on minimal performance criteria of building components defined by the client. So-called 'decisive performance requirements' are directly linked to 
the clients performance needs and a building component's specific performance. The performance criteria of building components, especially performance loss, are determined by assessing defects through visual inspections. A minimum percentage of measurements, taken randomly, should meet the criteria (Straub, 2007). Validation that the actual performance addresses the required performance by the clients is carried out by ongoing performance measurements by the contractor and through tenants surveys regarding the success of the actual performance of the facility to meet the required performance.

Within performance-based relationships, the selection of maintenance contractors is very important for the owner. Parties getting in the relationship should have similar views and should approach the relationship with similar perspectives. All members of the association of the Dutch medium-sized building maintenance employers 'vastgoed onderhoudsbedrijven (WVB)' have adopted the EFQM (European Foundation for Quality Management) Excellence Model. The fact that the contractor has to act as a maintenance-engineering consultant to the owner is vital for the PBM approach. The consultancy activities conducted by maintenance contractors for housing associations include: providing advice on maintenance strategies and design of maintenance scenarios, specifying maintenance activities, executing periodic performance measurements, and conducting tenants satisfaction surveys.

Maintenance contractors can be certified to work according to PBM methods and procedures by the quality mark for real estate PBM 'VastGoedOnderhoud Keur' (VGO KEUR) (Straub and Van Mossel, 2007; SCTV, 2005). The VGO KEUR includes a wide range of requirements: financial standards, and contractor's performance outcome. A drawback is that PBM competencies of contractors are only demonstrated by a well-documented process. Moreover the competencies scan primarily measures resources. Conversely, owner's satisfaction in maintenance-engineering consultancy is heavily determined by capabilities, such as communication and empathy skills.
Together with the integrity of the consultant, these seem to be the most important strategic capabilities of consultants from the viewpoint of the owner. Owners' satisfaction is determined by contractors' performance outcomes.

Housing associations that use PBM contracts acknowledge the importance of an intelligent client role (Straub, 2007: 139): “They need maintenance process managers with a thorough knowledge of functional needs, performance, procurement, legal issues, and access to high-level technical expertise (even if this has to be brought in from elsewhere)."

\subsection{Method of the study}

A quantitative model was developed that calculates the Net Present Value of the direct (product) and indirect (transaction) costs for a competitive maintenance tendering and for PBM contracts. Direct costs represent the product costs for maintenance. For the owner, actual payments to the contractor represent the product costs: the contract price. Indirect costs are the transaction costs by the owner and the contractor in connection with the procurement process (Table 1). Overall costs for the owner include the contract price and his own transaction costs.

Table 1. Classification of maintenance direct and indirect costs

\begin{tabular}{lll}
\hline & Direct costs & Indirect costs \\
\hline Project costs & $\begin{array}{l}\text { Product costs: } \\
\text { direct labour, }\end{array}$ & Transaction \\
& costs \\
& materials, & \\
& equipment, & \\
transport &
\end{tabular}

Non-project specific costs

$$
\begin{aligned}
& \text { Relationship- } \\
& \text { specific asset } \\
& \text { costs } \\
& \text { Overhead costs }
\end{aligned}
$$

Non-project specific costs are relationshipspecific asset and overhead costs of contractors. Relationship-specific assets have little value outside a particular relationship of an owner and a maintenance contractor. However, the costs of these assets are not-project specific but relationship-specific. In practice most con- 
tractors will be hired for several projects of an owner. Examples for relationship-specific asset costs are a performance measurement method of the contractor adapted to the needs of the owner and general agreements of owners and contractors. Relationship-specific asset costs and overhead costs were not implemented in the study.

The model used in a pilot study was evaluated with employees of maintenance contractors and housing associations. The adapted model links the maintenance scenario and direct costs calculation to the indirect costs calculation and is more user-friendly. This model includes project specific data, data about the maintenance scenarios (competitive and performance-based) and contract prices, and data about the indirect costs and the planning of future maintenance cycles. The initial process the first maintenance cycle - and the subsequent processes consist of all activities conducted during a maintenance cycle. Following the initial maintenance process, one or more subsequent processes will take place. It is assumed that these subsequent processes will be equal in scope and transaction costs, although the actual maintenance activities and product cost undertaken in each can vary. The competitive maintenance scenario exists of equal recurring product costs every maintenance cycle.

Table 2. Classification model for Indirect costs: time sheet for project time of the initial maintenance process

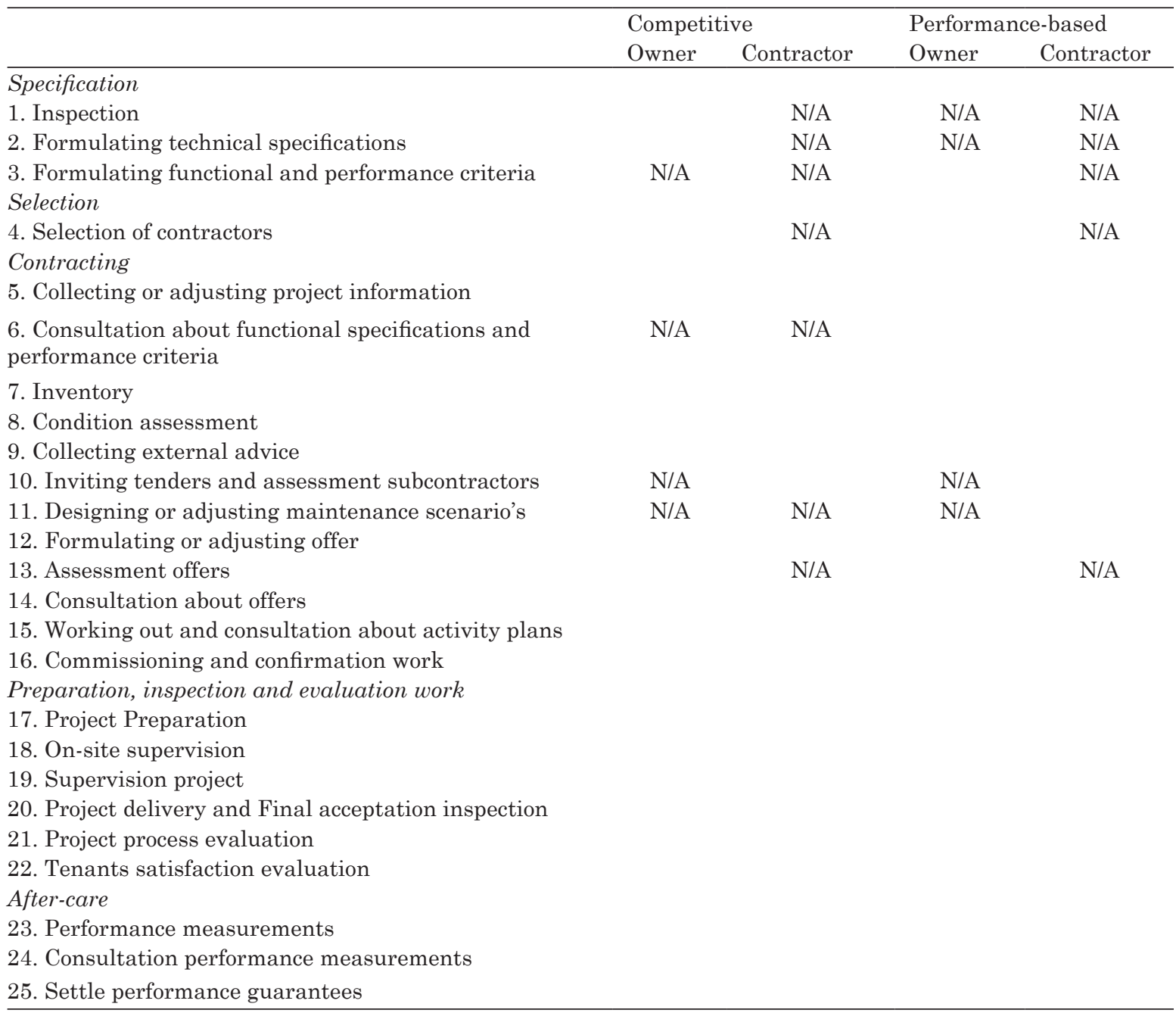

N/A = not applicable 
The developed indirect costs model involves transactions costs of the owner and the contractor. We term the costs related to the first state of the commercial process: "marketing contractor relation-specific transaction costs" or "overhead costs". In the long term PBM relationships contractors' involvements enclose a part of the whole service life of a building. Indirect costs depend on the process activities that must be conducted by the owner and the contractor respectively throughout the maintenance period of the complex. Costs for providing advice about maintenance solutions and for conducting performance measurement are considered part of the bid costs or priced separately.

The indirect costs model distinguishes 25 process activities based upon the competitive maintenance process and the PBM process. The activities in the initial and subsequent processes are clustered into five phases: (1) specification, (2) selection, (3) contracting, (4) preparation, supervision and evaluation, and (5) after-care. The activities within the preparation phase, supervision and evaluation do not involve the maintenance production itself.

Table 2 shows a simplified example of a time sheet of the indirect costs model. In each column the owner and the contractor has to fill in the hours spent on the activity. Labour costs are calculated depending on the wage scale. Costs are based on a differentiation in hourly rates per activity, with the rates level depending on wage categories applied by both the owner and the contractor. The model assumes that each party will have three such categories. Third parties, such as consultants or inspection agencies, may perform some activities; the costs involved being charged to the owner and/or contractor.

The study included 22 projects, each project involves exterior maintenance of housing estates owned and managed by a housing association. The projects are owned and managed by 13 different housing associations and maintained by 9 different contractors.

One of the projects is a residential building complex 'Eksterstraat' in Amersfoort. This complex exists of 104 single-family dwelling units, built in 1967. Maintenance activities are some replacements of windows, preventive wood work and repairs, and paintwork for a period of 30 years. The calculated direct costs in case of the PBM contracting are 13\% lower compared to the (theoretical) situation if the work was tendered competitively. The main reason is that a well-considered maintenance interval extension from 6 to 7 years. The indirect costs of the PBM contracting approach drop with more than 50\%, mainly in the subsequent processes (maintenance intervals).

\subsection{Findings}

From the results, the overall project costs for all kind of projects appear to be $20 \%$ lower for PBM than for competitive maintenance tendering. In all projects the direct costs (contract price minus the indirect costs of the contractor) of PBM are lower, or at worst the same, as for competitive maintenance tendering. The share of the indirect costs of the owner in the overall project costs for both tendering approaches is small (2-5\%). The costs savings on contract prices by PBM are the biggest for 'total maintenance projects', followed by 'simple projects' (Figure 1). 100\% in the figures refers to competitive maintenance tendering.

Indirect costs of the owner are lower in case of PBM in the initial process as well as in subsequent processes. On average in PBM the Indirect costs of the owner are 51\% lower (Figure 2).

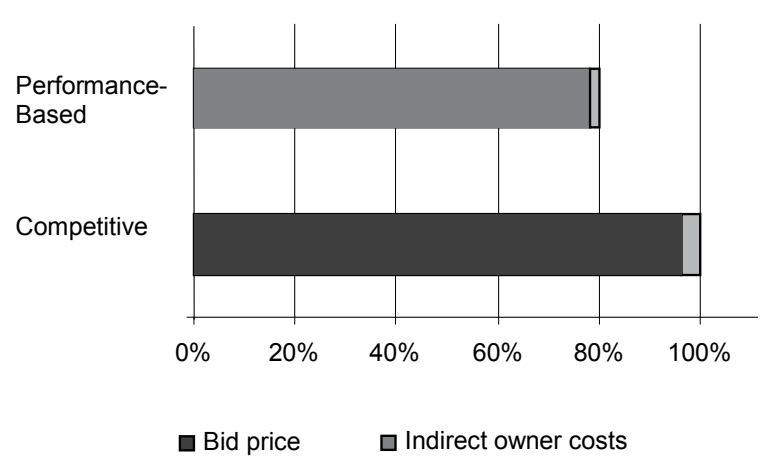

Figure 1. Average overall owner costs 


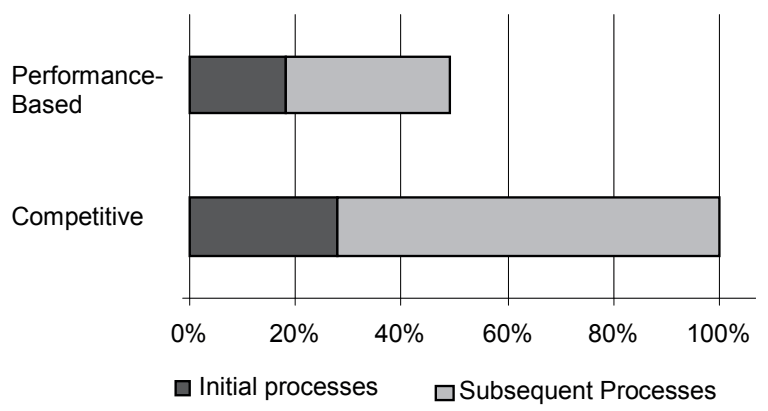

Figure 2. Average indirect costs of initial processes and of subsequent processes

PBM reduces both Direct and Indirect costs. The essential preconditions are long term involvement and freedom in the maintenance design and process for the contractor, giving opportunities for product and maintenance process improvements. The process phases 'specification', 'selection', 'contracting' and 'work and supervision' become markedly less costly in case of PBM. The 'after-care' phase is markedly more expensive tendering performance-based, because of conducting periodic performance measurements.

\section{Product quality}

The reduction of the product costs indicated that the product quality has been improved, e.g. cycles of maintenance activities could be extended. A broad-scale inventory of product quality improvement by PBM in the Netherlands is lacking. Output measurements, e.g. the technical performance of the maintained building components, are also not implemented yet in the quality mark VGO-KEUR.

In 2006 a standard for condition assessment of buildings has been introduced in the Netherlands (Straub, 2009a; Straub, 2009b). Based upon assessment of defects, and defect parameters importance, intensity, and extent, the condition of a building component is rated on a six-point rating scale. The third part of the standard will involve an aggregation of condition scores to a technical index of principal systems and the whole building, using a ten-point rating scale. Replacement costs are being used to weigh the building components. This new index provides an opportunity to benchmark building properties and to validate the effectiveness of PBM compared to prescriptive unit-price competitive bid procurement.

\section{THE ISRAELI PUBLIC FACILITIES MAINTENANCE SECTOR}

Israel's built public facilities may be classified into hospitals (2.0 M. sq. m.), clinics (1.0 M. sq. m.), public offices, public buildings such as courthouses (0.3 M sq. m.), etc. Maintenance services in most public organizations are contracted out through prescribed bill of quantities tenders in which the lowest bid is selected.

\subsection{Performance-Based-Maintenance (PBM)}

The Israeli standardization in maintenance of built facilities evolved in the past two decades from the British Standard BS 8210:1986 (1986). It is based on preventive PBM of the mechanical systems and along condition-based maintenance of the structural, exterior envelope, and interior finishes components of the building. The standard implies the appointment of a facility manager responsible for administering all necessary preventive and breakdown maintenance activities to maintain the building at a safe and sustainable condition. The standard does not indicate performance levels by which the building performance may be monitored; furthermore, it does not allow any consideration of the performance by the owner of the facility (Israel Standards Institution, 1999, 2002). As the buildings stock expanded in terms of complexity and performance requirements, development of a PBM standard is expected.

PBM was designed along the following guidelines:

- Given performance of the facilities at the beginning of the contract;

- Commitment of the contractor to provide maintenance services so as to meet performance at a predefined agreed level according to the performance model, i.e. a minimum of BPI (Building Performance Indicators) $>80$ as described below;

- Preventive maintenance of the core building systems: Electricity and HVAC, is carried out with core maintenance 
crew along the year, major preparatory preventive maintenance activities are scheduled towards the winter and summer: these activities are carried out with the aid of additional supporting staff allocated by the contractor as backup crews for peak-maintenance periods. This guideline allows the contractor to carry the majority of maintenance activities with core resource levelled body of manpower.

Owner/clients that implement PBM are capable of: (1) strategic policy making (long term objectives for the building stock and the performance), (2) established requirements of performance, and (3) high inspection capabilities (Shohet, 2006).

\subsection{Method of the study}

The study was designed to follow 5-steps as follows:

A - Benchmarking of the performance of the facilities under competitive prescribed specification and unit-price contract;

B - Development of performance specification and PBM Contract;

C - Setting outlines for PBM lump-sum tendering: definition of prequalification requirements, establishment of transfer mechanism of the facility, and definition of payments and monitoring milestones;

D - Implementation of PBM on a sample of 6 public facilities;

E - Comparison of performance and cost effectiveness of the maintenance of the facilities between years 2007 and 2008 according to 3 Key Performance Indicators (KPIs).

\section{Building Performance Indicator (BPI)}

This KPI is adapted here for public facilities; it monitors the physical state and fitness for use of the building and of the systems in it. The rationale behind this indicator is the need for a Life Cycle Cost-weighted score, scaled from 0 to 100 , to each of the principal building systems, expressing its physical and functional (performance) states. In all, 9 principal systems were defined in public office buildings. Each building system's score, defined as $P_{k}$, reflects three composites: its physical state, typi- cal failures and their frequency of occurrence, and the maintenance policy. The combination of the aforementioned composites represents the performance level of the system $\left(P_{k}\right)$. The weighting of a building system $\left(W_{k}\right)$ is obtained from cost shares of that system's components based on the Life Cycle Costs including installation, maintenance and replacement. The BPI is then calculated by multiplying of weights for each system as shown in Eq. (1):

$$
B P I=\sum_{k=1}^{n} P_{k} \times W_{k}
$$

BPI can be analyzed as follows:

- BPI > 80 indicates good state of the performance of the building or better;

- $70<\mathrm{BPI} \leq 80$ expresses satisfactory (80) or marginal (70) condition;

$-60<\mathrm{BPI} \leq 70$ reflects deterioration of the building; and

- $\mathrm{BPI} \leq 60$ means that the building is rundown.

Normalized Annual Maintenance Expenditure (NAME)

This KPI is introduced to neutralise the Annual Maintenance Expenditure (AME) from the effects of Age and Occupancy on the maintenance. NAME is defined as follows:

$$
N A M E_{y}=\frac{A M E_{y}}{A C_{y} * O C_{\mathrm{y}}}
$$

where: the $A M E_{y}$ is the Annual Maintenance Expenditure in (\$/sq.m.); $A C_{y}$ is the Age Coefficient for year $y$, and $O C_{y}$ is the Occupancy Coefficient (Shohet et al., 2003). These coefficients adjust the AME to prevailing occupancy condition and age of the building.

\section{Maintenance Efficiency Indicator (MEI)}

This KPI examines the maintenance efficiency with inputs such as BPI and $\mathrm{NAME}_{\mathrm{y}}$ as expressed in Eq. (3):

$$
M E I_{\mathrm{y}}=\frac{N A M E_{\mathrm{y}}}{B P I} * i_{p y},
$$

where: the $M E I_{\mathrm{y}}$ is the Maintenance Efficiency Indicator for year $y$; $i_{p y}$ is the trades and office buildings construction prices index published by the National Bureau of Statistics (Central Bureau of Statistics, 2012), and NAME $E_{y}$ is the 
Normalized Annual Maintenance Expenditure for year y according to expression (2) above. $M E I_{y}$ may vary between 0 and values above it.

For a typical office building with reinstatement value of US $\$ 1,180$, annual maintenance costs of US $\$ 30$ and expected performance of $\mathrm{BPI}=100$, standard occupancy and Age Coefficient of 1.0, this indicator yields the value of 0.30 .

$\mathrm{MEI}_{\mathrm{y}}$ for public buildings is inferred as follows:

$-\mathrm{MEI}_{\mathrm{y}}<0.24$ represents a state in which either the budgetary investment is low or the efficiency of the utilization of maintenance resources is high, or both;

$-0.24 \leq \mathrm{MEI}_{\mathrm{y}} \leq 0.36$ represents the desirable situation of maintenance with sound correlation between the maintenance resources and the actual performance;

- $\mathrm{MEI}_{\mathrm{y}}>0.36$ indicates high inputs relative to the actual performance. This may express either high expenditure or low physical performance or a combination of both situations.

The threshold values of 0.24 and 0.36 were defined according to the standard deviation of the normative value of 0.30 for office and public facilities. The threshold values express a solid variance of 0.20 i.e. the coefficient of variance is 0.20 .

\subsection{Profile of the public facilities sample in Israel}

A two-year study was carried out in six public facilities owned by the government, serving civil servants and public, and maintained by a contractor that is selected based on quality (30\%) and price (70\%). The Total floor area of the buildings is 37,200 sq. m., indicating an average floor area of 6,206 sq. m. The mean age of the buildings is 35 years, and the mean occupancy is 117 visitors per sq. m./year, indicating relatively low occupancy compared with standard occupancy of 175 visitors per sq. m./ year.

\subsection{Findings}

A preliminary field survey of the performance of the facilities was carried out in 2007, during this year the maintenance of the facilities was carried out based on a conventional prescribed specification and unit-price competitive bid. In the end of 2007 a PBM lump-sum contract was developed and in 2008, the maintenance of the facilities was carried out along the outline of PBM. The performance and effectiveness of the sample of the facilities was reassessed in the end of 2008 and compared with those of year 2007.

Performance of the facilities according to the BPI improved in average from 73.6 to 79.8 by the end of 2008. This improvement was consistent in all the facilities in the sample. The average Normalized Annual Expenditure (NAME) was reduced by more than $20 \%$ and the Maintenance Efficiency indicator depicted an improvement in efficiency by $20 \%$ as well (from 0.42 to 0.33 ). Comparison of the BPI vs. the NAME explores that after one year of PBM lump-sum procurement the facilities sample is found in a consistently higher performance and within the boundaries of the normative range of efficiency $(\mathrm{MEI}=0.33)$. This may be virtually seen in Figure 4 as in 20085 out of the 6 facilities are found in the normative range of $0.24 \leq \mathrm{MEI} \leq 0.36$, while in 2007 only 2 of the facilities were found in the normative range (Figure 3). This case demonstrates a cost savings potential of implementing PBM of $20 \%$. The cost savings in this example were achieved by the following amendments: (1) reduced number of core personnel that have become possible thanks to the concise periodic activities at two peak periods (toward winter and summer); (2) extension of the replacement

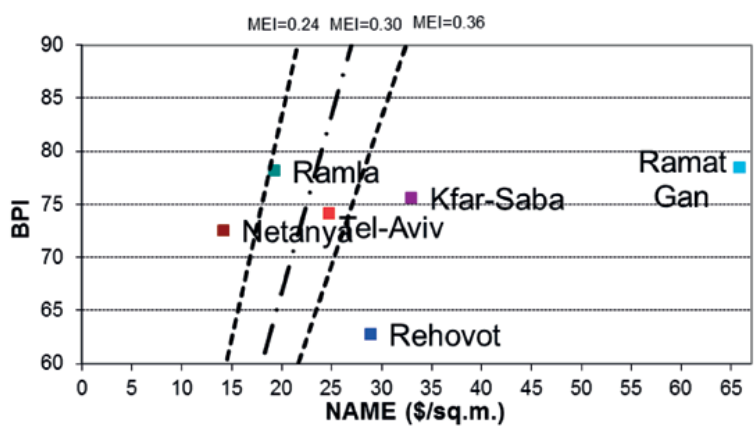

Figure 3. BPI Vs. NAME for the public facilities sample 2007 


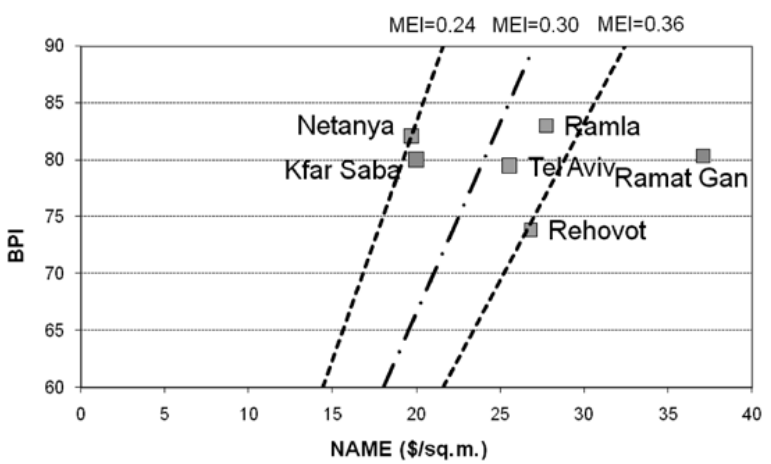

Figure 4. BPI Vs. NAME for the public facilities sample 2008

periods in some components, such as roofing, and exterior claddings; (3) reduced stock of spare parts (for plumbing, electricity, and interior finishing); and (4) reduced direct inspection costs, as inspection was concentrated in performance rather than in resources and execution.

\section{COMPARISON BETWEEN THE STUDIES}

A comparative study of PBM pilot projects carried out in the Netherlands and in Israel was carried out in 2009, with reference to years 2008 and 2007. Review of the maintenance sectors in both countries depicts that PBM contracting in the Facilities Management (FM) sector stem from the performance concept in construction. It is being implemented only in the maintenance public sector.

Table 3 comparatively summarizes key factors in PBM contracting as deduced from the outlines and outcomes of both studies: Procurement model, Contractors' services, Maintenance Management, Performance Management, Total costs and Performance outcomes. The comparison between PBM contracting key factors depicts that a bid on a combination between quality and price was adopted in both studies; the assessment of quality was carried out based on engineering consultancy capabilities, the assessment of the professional profile of previous projects, and body of technical staff (Quality and Availability). In the Netherlands as well as in Israel the contractors are asked for engineering-consultancy services next to the execution of maintenance activities. Planning of maintenance activities was carried out in Israel according to seasonal guidelines as a means for maintenance resource levelling. In the Netherlands the planning of maintenance activities is based upon performance measurements by the contractor; the planning covers preventive maintenance activities as well as repairs and replacements of components. Validation that the actual performance addresses the required performance by the clients is carried out by on-going performance measurements by the contractor and through tenant

Table 3. Comparison between key factors of PBM contracting between the Netherlands and Israel

\begin{tabular}{|c|c|c|}
\hline Key factors & The Netherlands & Israel \\
\hline Procurement model & $\begin{array}{l}\text { Performance specifications, Unit prices, } \\
\text { PBM qualifications (VGO-KEUR) }\end{array}$ & $\begin{array}{l}\text { Performance specifications, } \\
\text { Lump sum, Quality-price bid, } \\
\text { PBM qualifications, }\end{array}$ \\
\hline Contractors' services & Engineering-consultancy & Engineering-consultancy \\
\hline Maintenance management & $\begin{array}{l}\text { Preventive maintenance, repairs, } \\
\text { replacements }\end{array}$ & $\begin{array}{l}\text { Preventive maintenance, } \\
\text { seasonal maintenance }\end{array}$ \\
\hline Performance management & $\begin{array}{l}\text { Performance criteria building } \\
\text { components, preliminary condition } \\
\text { survey, on-going performance } \\
\text { measurements, tenant surveys }\end{array}$ & $\begin{array}{l}\text { KPIs: BPI, NAME, MEI, } \\
\text { Preliminary survey, on-going } \\
\text { surveys }\end{array}$ \\
\hline Total costs & $-20 \%$ & $-20 \%$ \\
\hline Performance outcomes & Not assessed & $+5 \%$ \\
\hline
\end{tabular}


surveys regarding the success of the actual performance of the facility to meet the required performance.

Comparison of the costs savings between the studies depicts that $20 \%$ reduction in costs was found in both studies, this reduction is attributed to reduction in direct costs and in indirect costs such as transactions and non project relationship specific asset costs such as consultancies. In the Netherlands the performance outcome were not assessed. The contractors take responsibilities and risks for longer term performance of the components. One may expect that the PBM performance is higher. The maintenance performance was monitored and compared in the Israeli study: an improvement of more than 5\% was inspected according to the BPI (from 73.6 to 79.8 ).

\section{DISCUSSION}

The study investigates the capability of PBM Contracts for outsourcing of Maintenance in public Facilities; The principles of PBM were briefly outlined: these principles include: technical prequalification of the contractors, performance scales for buildings systems maintenance performance monitoring, performance specification of maintenance, establishment of payment and performance monitoring mechanisms, and risk sharing model. These principles were implemented in pilot studies in the Netherlands and in Israel. Key factors of PBM were identified as: Bid on quality and price, requirement of consultancy qualifications on the contractor side, planning of maintenance activities according to seasonal guidelines as a means to provide the contractor with efficient resource levelling.

The findings reported from both pilot studies depict an improved performance following the implementation of PBM in the facilities. The efficiency with which the resources were used was found to be $20 \%$ better in both studies. This improved performance is attributed to the following principle drivers: a) PBM provided decisive criteria for monitoring facilities performance, these criteria improved the quality control (contractor) in the Dutch study and the quality assurance process (owner) in both studies;

b) Pre-Qualification requirements focused in technical capabilities of the contractor stimulated the development of consultancy capabilities of the contractors, these Pre Qualifications (PQ) improved the quality and efficiency of the operations and contributed to reduced number of claims and disputes along the implementation of the contract;

c) As the contract is on a lump-sum basis, the management and administration of the contract requires less bureaucracy in Israel. In the Dutch case the adoption of a lump-sum model is barred due to risk barriers on the contractors' side;

d) The tendering system is developed so as to include a greater share of quality (30-70\% of the total tender grade), this improved the effectiveness of the tendering process.

The latter conclusions foster the development of FM and Maintenance standardizations that will stimulate the application of PBM tendering by establishment of performance monitoring scales, and standard contract for PBM that will address the pre-qualification and tendering issues.

\section{REFERENCES}

British Standard BS 8210:1986 (1986) Guide to building maintenance management. British Standards Institution.

Central Bureau of Statistics (2012) Trade and office buildings construction inputs prices index. [Online] Available at: http://www.cbs.gov.il/ [accessed May 2012] (In Hebrew)

Cheng, Y. M. and Leu, S. S. (2008) Constraint-based clustering model for determining contract packages of bridge maintenance inspection, Automation in Construction, 17(6), pp. 682-690. http://dx.doi. org/10.1016/j.autcon.2007.12.001

Damnjanovic, I. and Zhang, Z. (2008) Risk-based model for valuation of performance-specified pavement maintenance contracts, Journal of Construction Engineering 
and Management, 134(7), pp. 492-500. ASCE. http:// dx.doi.org/10.1061/(ASCE)0733-9364(2008)134:7(492)

Israel Standards Institution (1999) Israel Standard 1525 part 1 "Buildings Maintenance Management: Elements and finish". Israel Standards Institution, Tel Aviv, Israel. (In Hebrew)

Israel Standards Institution (2002) Israel Standard 1525 part 2 "Buildings Maintenance: Residential Buildings and their nearby surroundings - service systems". Israel Standards Institution, Tel Aviv, Israel. (In Hebrew)

Lugtigheid, D., Jardine, A. K. S. and Jiang, X. (2007) Optimizing the performance of a repairable system under a maintenance and repair contract, Quality and Reliability Engineering International, 23(8), pp. 943-960. http://dx.doi.org/10.1002/qre.859

Nieboer, N. and Gruis, V. (2004) The Netherlands. In: Gruis, V. and Nieboer, N. (eds.), Asset management in the social rented sector: Policy and practice in Europe and Australia, Springer/Kluwer Academic Publishers, Dordrecht, pp. 185-208.

Priemus, H. (2001) Social housing as a transitional tenure? Reflection on the Netherlands' New Housing Memorandum 2000-2010, Housing Studies, 16(2), pp. 243-256. http://dx.doi.org/10.1080/713670004

Shohet, I. M. (2006) Key performance indicators for strategic healthcare facilities maintenance, Journal of Construction Engineering and Management, 132(4), pp. 345-352. ASCE. http://dx.doi.org/10.1061/ (ASCE)0733-9364(2006)132:4(345)
Shohet, I. M. (2003) Building evaluation methodology for setting maintenance priorities in hospital buildings, Construction Management and Economics, 21(7), pp. 681-692. http://dx.doi. org/10.1080/0144619032000115562

Stenbeck, T. (2008) Quantifying effects of incentives in a rail maintenance performance-based contract, Journal of Construction Engineering and Management, 134(4), pp. 265-272. ASCE. http://dx.doi.org/10.1061/ (ASCE)0733-9364(2008)134:4(265)

SCTV (2005) Approval scheme quality mark for real estate maintenance (VGO Keur), Stichting Certificate Technisch Vastgoedbeheer (SCTV), Rotterdam (in Dutch).

Straub, A. (2007) Performance-based maintenance partnering: A promising concept, Journal of Facilities Management, 5(2), pp. 129-142. http://dx.doi. org/10.1108/14725960710751870

Straub, A. (2009a) Cost savings from performance-based maintenance contracting, International Journal of Strategic Property Management, 13(3), pp. 205-217. http://dx.doi.org/10.3846/1648-715X.2009.13.205-217

Straub, A. (2009b) Dutch standard for condition assessment of buildings, Structural Survey, 27(1), pp. 23-35. http://dx.doi.org/10.1108/02630800910941665

Straub, A. and Van Mossel, H. J. (2007) Contractor selection for performance-based maintenance partnerships, International Journal of Strategic Property Management, 11(2), pp. 65-76. http://dx.doi.org/10. 1080/1648715X.2007.9637561 